\title{
Dietary Supplementation of Phytoncide and Soybean Oil Increases Milk Conjugated Linoleic Acid and Depresses Methane Emissions in Lactating Holstein Cows
}

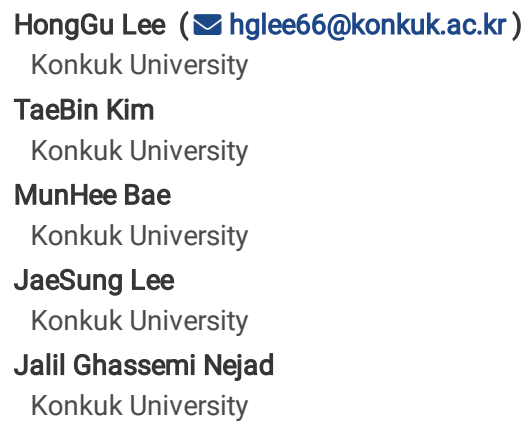




\section{Abstract}

The objective of this study was to determine whether adding phytoncide oil (PO) and soybean oil (SBO) to the dairy cow diet could increase milk conjugated linoleic acid (CLA) and depress methane $\left(\mathrm{CH}_{4}\right)$ emissions in lactating Holstein cows. Rumen fermentation was conducted at four levels of SBO $(0,1,2$, and $4 \%$, on DM basis) and two levels of PO ( 0 and $0.1 \%$, on DM basis) with in vitro experiment. To evaluate blood parameters, fecal microbe population, milk yield fatty acid compositions, and methane production, in vivo experiment was conducted using 38 Holstein dairy cows divided into two groups of control (fed TMR) and treatment (fed TMR with $0.1 \% \mathrm{PO}$ and $2 \%$ SBO as DM basis). In the in vitro study (Experiment 1 ), PO or SBO did not affect ruminal pH. However, $\mathrm{SBO}$ tended to decrease ruminal ammonia- $\mathrm{N}(p=0.099)$. Additionally, $\mathrm{PO}$ or SBO significantly decreased total gas production $(p=0.041$ and $p=0.034$, respectively). Both PO and SBO significantly decreased methane production $(p<0.05)$. In addition, PO significantly increased both CLA (c9, t11 and t10, c12 CLA) $(p<0.001)$. Collectively, $0.1 \%$ PO and $2 \%$ SBO was selected that improved CLA and methane production most effectively and did not induce abnormal ruminal fermentation. In the in vivo study (Experiment 2), $0.1 \%$ PO with $2 \%$ SBO (PSO) did not affect CBC. However, it decreased BUN and MG levels in blood ( $p$ $=0.021$ and $p=0.01$, respectively). PSO treatment decreased pathogenic microbes $(p<0.05)$. It increased milk yield $(p=0.017)$ but decreased percentage of milk fat $(p=0.013)$ and decreased MUN level $(p<0.01)$. In addition, PSO treatment increased both CLA and PUFA in milk ( $p<0.01)$. Finally, it decreased methane emissions from dairy cows. These results provide compelling evidence that PSO supplemented with a TMR-based diet can simultaneously increase CLA synthesis and decrease methane production with no influence on the percentage of milk fat in lactating Holstein cows.

\section{Introduction}

Recently, research on various health and eco-friendly substances is being conducted due to the ever-increasing interest in consumer health. Several studies have shown that plant or plant extracts can increase production quality in cows, including conjugated linoleic acid (CLA) ${ }^{1}$. CLA is known as a functional natural product that is produced in the rumen. It has been proven to have many beneficial effects on the health of humans. In addition, CLA has been shown to be an effective anticancer agent ${ }^{2}$. It is an antioxidant ${ }^{3}$. It can improve atherosclerosis ${ }^{4}$ and immune response ${ }^{5}$. CLA can also lower cholesterol ${ }^{6}$ and prevent diabetes ${ }^{7}$. According to previous research, although CLA form may vary greatly, cis-9, trans-11 CLA is the main form and its role is the greatest among all forms. Interestingly, cis-9, trans-11 CLA levels in ruminant products are higher than those in other animal products. This is because the cis-9, trans-11 CLA can be produced by microbes in the rumen of ruminant. To increase cis-9, trans- 11 CLA levels in ruminant products, lots of soybean and sunflower compounds have been used because they contain high levels of linoleic acid ${ }^{8,9}$. Their extract in oil form is known to be the direct source that can increase LLA $^{10}$ and inhibit methane production 11,12. Although such sources of plant oil contain considerable linoleic acid, they also have a negative effect of increasing trans-10, cis-12 CLA which inhibits the synthesis of milk fatty acids ${ }^{13-15}$. Phytoncide oil (PO) has attracted attention as an additional source to deal with such problem. POs are secondary metabolites from many plants ${ }^{16}$. PO has been reported to show antimicrobial properties similar to tannin and saponin ${ }^{17,18}$. This is because PO contains a large amount of $\beta$-carotene which is effective in regulating Gram-negative and Gram-positive bacteria ${ }^{19}$ known to participate in the metabolism of fatty acid in rumen, termed bio-hydrogenation.

From what we discussed above and according to Oh et al. ${ }^{20}$, plant extracts can increase propionate and decrease acetate. Propionate can regulate methane production in rumen ${ }^{20,21}$. Biohydrogenation is involved in the metabolism to produce CLA from linoleic acid. It is related to the formulation of methane and volatile fatty acid (VFA) because of their competition with hydrogen ion ${ }^{12,22}$. Based on our previous study, we hypothesized that combining soybean oil (SBO) with phytoncide oil from pine nut cone (PO) could increase CLA yield and decrease methane production, while maintaining or increasing milk fat, by regulating the formulation of methane and VFA in rumen. There is a lack of information as to whether phytocides can affect final ruminant production and reduce methane emissions. Therefore, the objective of this study was to investigate in vitro and in vivo effects of phytocide oil plus soybean oil on increasing milk CLA and depressing methane emissions in lactating Holstein cows.

\section{Materials And Methods}

\section{Experimental materials and procedures for in vitro experiment}

The procedures involving animals in this study followed the ARRIVE guidelines. All cannulation procedures involving animals were performed according to the Animal Experimental Guidelines in Konkuk University and the ethical approval was obtained by the Animal Care and Use Committee (IACUC) of Konkuk University, Republic of Korea (Approval No.: KU18058).

The ruminal fluid was collected after filtering with two layers of cheese cloth through rumen cannula at 2 hours before feeding. The collected ruminal fluid was kept in a $2 \mathrm{~L}$ thermos bottle that was filled with preheated $\mathrm{CO}_{2}$ gas and with oxygen $\left(\mathrm{O}_{2}\right)$ completely removed, maintained at $39^{\circ} \mathrm{C}$, and then moved to the research lab. After removing feed particles by vacuum pump, the supernatant was used for the test.

The basal diet was dried in a drying oven (JS-CO2-AT100, Johnsam Co., Ltd. Bucheon, Korea) at $60^{\circ} \mathrm{C}$ for 24 hours. The forage and concentrate were then crushed with a $2 \mathrm{~mm}$ screen and used as a TMR at a ratio $6: 4$. Then $0.2 \mathrm{~g}$ of TMR and $20 \mathrm{~mL}$ of anaerobic McDougall buffer ${ }^{23}$ were added to a $60 \mathrm{~mL}$ serum bottle containing $10 \mathrm{~mL}$ of ruminal fluid. After adding $30 \mathrm{~mL}$ of culture solution to the culture bottle, two levels of PO $(0$ and $0.1 \%$ on DM basis arranged by Phylus Co., Ltd. Seoul, Korea) were added according to each treatment and four levels of SBO (0, 1, 2, and $4 \%$ on DM basis arranged by Haepyo Co., Ltd) as a precursor of CLA in the rumen were added, respectively. Each ruminal sample was kept at the maximum anaerobic conditions by flushing with $\mathrm{CO}_{2}$ gas and capping with a rubber cap and an aluminum cap to prevent gas leakage as much as possible. The experiment was conducted with 8 treatments (three replicates per treatment) at time intervals of $0,6,12,24,48 \mathrm{~h}$ in a shaking incubator (JSP Corp, SI-900R; $100 \mathrm{rpm}$ ) at $39^{\circ} \mathrm{C}$. 


\section{Analysis}

After each incubation, total gas and methane were detected and the portion of ruminal sample was distributed for analysis of pH, VFA, ammonia- $\mathrm{N}$, and fatty acid. Measurement of total gas was conducted using a $50 \mathrm{~mL}$ gas cylinder (Habdong Co., Anyang, Korea). Methane was detected using a Gas Chromatography/TCD (HP 6890, Hewlett Packard Co., CA, USA) equipped with an HP-PLOT-A column (dimension: $30 \mathrm{~m} \times 0.32 \mathrm{~mm} \times 20.00 \mu \mathrm{m}$ ) according to Owen et al. ${ }^{24}$. Culture solution of $2 \mathrm{~mL}$ was collected for ammonia $(1 \mathrm{~mL})$ and VFA analyses $(1 \mathrm{~mL})$. All samples collected were kept frozen at $-20{ }^{\circ} \mathrm{C}$ until analyzed. Ammonia concentration was determined with the method of Fawcett and Scott ${ }^{25}$ using a spectrophotometer (Model 680, BIO-RAD, CA, USA). Culture solution of $1 \mathrm{~mL}$ was mixed with $0.1 \mathrm{~mL} 25 \%$ phosphoric acid. Then $0.2 \mathrm{~mL}$ pivalic acid solution $(2 \%$, w/v) was added as an internal standard. The mixed solution was centrifuged at $15,000 \times g$ for $15 \mathrm{~min}$ and the supernatant was used to determine the concentration and composition of VFA using a gas chromatograph (HP 6890, Agilent Technologies, Santa Clara, CA, USA). Incubation solution of $20 \mathrm{~mL}$ for long chain fatty acids was also collected at each incubation time and freeze dried. Lipids were extracted using Folch's solution and analyzed with the gas chromatograph/FID (HP 7890 series GC System, Agilent technologies, California, USA) equipped with an Sp-2560 capillary column (dimension: $100 \mathrm{~m} \times 0.25 \mathrm{~mm} \times 0.2 \mu \mathrm{m}$ film thickness).

\section{Animals and design for in vivo experiment}

A total of 38 Holstein dairy cows (milk fat: $5.0 \pm 0.30 \%$; milk yield: $37.1 \pm 2.85 \mathrm{~kg} / \mathrm{d} /$ head; days in milk: $99.4 \pm 24.32 ;$ parity: $3.1 \pm 0.68$ ) were randomly assigned to two groups to analyze milk fatty acids, methane production, fecal microbe population, and blood parameters and studied for 35 days. The cows were housed in a roofed shelter equipped with sunlight-roof and bedded with dry manure for comfort ( $4.5 \mathrm{~m}^{2}$ per cow). Sunlight-roof covered the barn and winch curtain helped ventilation. The cows were fed in mangers and each pen was equipped with separate water throughs. The procedures involving animals in this study followed the ARRIVE guidelines. The ethical procedure was according to the Animal Experimental Guidelines in Konkuk University and approved by the Animal Care and Use Committee (IACUC) of Konkuk University, Republic of Korea (Approval No.: KU18058).

\section{Diets and treatments}

Dairy cows were fed total mixed ration (76.8\%), roughage (8.4\%), and concentrated feed (14.8\%). These experimental diets were formulated to meet or exceed the NRC recommendations ${ }^{26}$. They were provided for ad libitum intake. Supplemental Table S1 shows ingredients and chemical compositions of the experimental diet. According to results of in vitro experiment, PSO (0.1\% PO and $2 \%$ SBO on DM basis) were mixed with the vehicle and added to the TMR by top dressing. The control group (Control) was fed TMR added with the same amount of vehicle (not including PO or SBO).

Feed samples were analyzed for dry matter (DM), crude protein, ether extract, crude fiber, crude ash, neutral detergent fiber (NDF), and acid detergent fiber (ADF) according to AOAC (1990) procedures. DM content was determined by drying samples in a vacuum oven at $100^{\circ} \mathrm{C}$ overnight. Ash content was determined by incineration at $550^{\circ} \mathrm{C}$ overnight in a muffle furnace. Crude protein ( $\left.\mathrm{N} \times 6.25\right)$ was determined using the Kjeltec System (Kjeltec 2400 , FOSS, Hillerød, Denmark). Crude fiber, NDF, and ADF contents of feed samples were analyzed using a Fibertec System (Fibertec 2010, FOSS, Hillerød, Denmark). Ether extract contents were determined using an ether extraction system (ANKOM XT15 Extractor, ANKOM Technology, NY, USA). Mineral contents of the feed were determined with inductively coupled plasma optical emission spectrometry (ICP-OES, Thermo, Waltham, MA, USA).

\section{Blood collection and analysis}

For blood cell counting and metabolite analysis, blood samples were collected from each Holstein dairy cow via a jugular vein at $3 \mathrm{~h}$ before feeding and at 0 , 21, and 35 days after feeding. Using EDTA tube (BD 367844 Vacutainer, Becton Dickinson, NJ, USA), whole blood was subjected to complete blood count (CBC) test using a VetScan HM2 Hematology System (Abaxis, Union City, CA, USA). In addition, the plasma portion of blood was obtained by using heparin tube (BD 367874 Vacutainer, Becton Dickinson, NJ, USA) and centrifuging at 3,000 rpm for 15 min in order to determine blood metabolites using a Chemistry analyzer (Furuno CA-270, Nishinomiya, Japan).

\section{Fecal collection and analysis of microbes}

Feces were collected on the same day at the same time as blood sampling. They were obtained from each lactating Holstein cow from the rectum, kept in liquid nitrogen, transferred into ice box at $-4^{\circ} \mathrm{C}$, transported to laboratory, and maintained in a deep freezer $\left(-80^{\circ} \mathrm{C}\right)$ until analysis. One gram of fecal sample was diluted with $10 \mathrm{~mL}$ of $0.85 \% \mathrm{NaCl}$ solution. Then $1 \mathrm{~mL}$ of the mixture was subjected to ten-fold serial dilution $\left(10^{1}\right.$ to $\left.10^{11}\right)$. The dilution was vigorously shaken with a vortex mixer. Then $0.1 \mathrm{~mL}$ of the dilution was spread onto a agar plate. Enumeration of bacteria was performed on MRS agar plates for Lactobacillus spp. and LB agar (Luria-Bertani broth diluted with bacto agar) plates for bacillus spp. Plates were incubated in anaerobic condition at $37^{\circ} \mathrm{C}$ for $24 \mathrm{~h}$. Under the same condition, enumeration was done for pathogenic microbes Salmonella and E. coli on MacConkey agar plates. The number of colony-

forming unit (CFU) was expressed as

$$
\log _{10} \frac{C F U}{g} \text { feces. }
$$

\section{Methane emission analysis}


At $0,7,21$, and $35 \mathrm{~d}$, measurement of methane emission was conducted using Laser Methane mini-Green (LMm-G; Tokyo gas engineering solution, Tokyo, Japan). Between 10:00 and 11:00 hours when gas emission was the most active during feed intake, methane emission levels from all dairy cows in each group were measured in triplicates. To increase the reliability of measurement, a fixed distance was used for each measurement and external environment (temperature, humidity, wind speed) was also measured. Finally, the total ppm value was calculated for each treatment by dividing the value of ppm-m (parts per million $\times$ meter) to the distance (meters) measured after derivation.

\section{Milk collection and analysis}

During the experimental period, milk was collected twice a day (at 3 am and $3 \mathrm{pm}$ ). Total milk yield was then calculated and the mean milk yield for 7 days was measured. At the end of the experiment, average milk yield was calculated. After mixing the collected milk in the morning and afternoon at each sampling day $\left(0,21\right.$ and 35 days), samples were stored at $4^{\circ} \mathrm{C}$ for milk composition analysis. Subsamples were stored at $-20^{\circ} \mathrm{C}$ for fatty acids analysis.

Milk composition was measured with a MilkoScan (CombiFoss FT+500 S/H, Hillerød, Denmark). Milk lipids were extracted and detected using the same methods as described above for the in vitro experiment. Analysis conditions were: Sp-2560 capillary column (dimension: $100 \mathrm{~m} \times 0.25 \mathrm{~mm} \times 0.2 \mu \mathrm{m}$ film thickness); injection:split, $30: 1$; heater temperature, $255^{\circ} \mathrm{C}$; pressure, $32.64 \mathrm{psi}$; total flow, $39.5 \mathrm{~mL} / \mathrm{min}$; split flow, $36.0 \mathrm{~mL} / \mathrm{min}$; injection volume, $1.0 \mu \mathrm{L}$; carrier gas, helium $1.2 \mathrm{~mL} / \mathrm{min}$; oven program, 70 to $100^{\circ} \mathrm{C}$ at $5^{\circ} \mathrm{C} / \mathrm{min}$ and hold for $2 \mathrm{~min}$, then 100 to $175^{\circ} \mathrm{C}$ at $10^{\circ} \mathrm{C} / \mathrm{min}$ and hold for $40 \mathrm{~min}$, then 175 to $225^{\circ} \mathrm{C}$ at $5^{\circ} \mathrm{C} / \mathrm{min}$ and hold for $40 \mathrm{~min}$; detector, FID System; and heater temperature, $260^{\circ} \mathrm{C}\left(\mathrm{H}_{2}\right.$ flow: $40 \mathrm{~mL} / \mathrm{min}$, air flow: $\left.400 \mathrm{~mL} / \mathrm{min}\right)$.

\section{Statistical analyses}

Results obtained from in vitro and in vivo experiments were subjected to least squares analysis of variance according to ANOVA and MIXED procedure of SAS (SAS Inst., Inc., Cary, NC, USA), respectively. Duncan multiple range test was used for ranking treatment means within a significant $\mathrm{F}$ test. Animals in in vivo were randomly assigned to control and treatment groups based on completely randomized design. Statistical differences were considered significant at $P<$ 0.05 Differences among means with $0.05<P<0.10$ were accepted as representing tendencies of differences.

\section{Results}

\section{In vitro experiment}

The Changes in ruminal $\mathrm{pH}$, ammonia- $\mathrm{N}\left(\mathrm{NH}_{3}-\mathrm{N}\right)$ and gas production is shown in Table 1. Oil supplementation materials did not affect the $\mathrm{pH}$ of the culture solution over the incubation time. No significant differences were observed in ammonia-N concentration by phytoncide oil. However, numerically lower values were observed in phytoncide oil treatments. In contrast, ammonia concentration was increased by SO treatment $(p=0.099)$.

The production of total gas and methane was detected by using GC at 0,12, 24 and $48 \mathrm{~h}$ incubation time. There were significant decreases in the production of total gas and methane among treatment groups $(p<0.05)$. Total gas production was lower $(p=0.041$ and 0.034 , respectively) when PO or SBO was added, especially from $48 \mathrm{~h}$ incubation. Additionally, from $6 \mathrm{~h}$ incubation, methane production was lower $(p<0.05)$ in treatment groups containing PO or soybean oil. Except for $12 \mathrm{~h}$ incubation, methane was much lower $(p<0.05)$ when both PO and SBO were added to the diet, compared with separate supplementation and the most decreases in methane was observed when $0.1 \% \mathrm{PO}$ and $2 \% \mathrm{SBO}$ supplementation.

The properties of volatile fatty acids at $48 \mathrm{~h}$ incubation time was analyzed by using GC (Table 2). There was no significant difference in individual VFAs.

In the variation of long chain fatty acids. From 6 to $48 \mathrm{~h}$, the trans vaccenic acid (TVA) was higher $(p<0.05)$ in treatment groups containing PO or SBO, except for $4 \%$ dosage (Table 3). Additionally, linoleic acid was higher $(p<0.001)$ at all time in the treatment groups containing PO or SBO. From $24 \mathrm{~h}$ incubation, both conjugated linoleic acids ( $99, \mathrm{t} 11 \mathrm{CLA}, \mathrm{t} 10, \mathrm{c} 12 \mathrm{CLA})$ were higher $(p<0.001, p<0.05)$, and total CLA was significantly higher $(p<0.001)$ in the P0 treatment groups than the non-PO treatment groups. Additionally, soybean oil significantly increased CLA at 24 and $48 \mathrm{~h}$ after incubation $(p<0.05$ at $24 \mathrm{~h}, p<0.001$ at $48 \mathrm{~h}$ ). Moreover, more higher CLA level from 24 to $48 \mathrm{~h}$ was observed in the treatment group containing more SBO with PO ( $p<0.05)$.

Collectively, $0.1 \%$ PO and $2 \%$ SBO supplementation on TMR was selected for in vivo study because its dosage indicated most activation of inducing hydrogen ion from methane production to biohydrogenation of fatty acids when considering the result of most decrease in methane and increase in CLA simultaneously with no influence on ruminal fermentation.

\section{In vivo experiment}

\section{Blood analysis}

The result of $\mathrm{CBC}$ analysis was conducted by using whole blood (Supplemental Table S2). There were no significant differences in white blood cells, red blood cells, hemoglobin, hematocrit, mean corpuscular volume, and mean corpuscular hemoglobin or mean corpuscular hemoglobin concentration between the PSO treatment and control groups. In the result of the blood metabolic parameters (Supplemental Table S3), There was no significant difference ( $p>0.05)$ in most of the parameters, except for blood urea nitrogen (BUN) and magnesium (MG). The two metabolites, BUN and MG, were lower ( $p=0.021, p=0.01)$ in the PSO treatment group. 


\section{Fecal microbes}

The beneficial microbes in the fecal were not affected by the treatment. However, the pathogenic microbes were significantly lower $(p<0.05)$ from 21 to $35 \mathrm{~d}$ in the fecal of the PSO treatment group (Figure 1).

\section{Milk yield, composition and fatty acids}

In the result of milk yield. There was no difference from the initiation of the study until 2 weeks. However, from $15 \mathrm{~d}$, an increase ( $p<0.01)$ in milk yield was observed in the PSO group (Table 4). Thus, the total average of milk yield was higher $(p=0.017)$ in the PSO group than in the control group. Although milk fat content (\%) was lower in PSO group, 4\% FCM was not difference between two groups. In addition, lower value of MUN was observed $(p<0.01)$ in the treatment group (Table 5). Although the metabolites of CLA, stearic acid, or trans vaccenic acid were not changed consistently, cis-9, trans- 11 CLA in milk was higher at nearly double $(p<0.01)$, and trans- 10 , cis- 12 CLA was higher $(p<0.05)$ in the treatment group. Additionally, the total CLA was higher $(p<0.01)$ in the PSO group (Table 6).

\section{Methane emission analysis}

The analysis of methane emission from the cows was conducted by using laser detector in each group (Figure. 2). There were 4 detection times during the experiment at $(0,7,21,35) \mathrm{d}$. Although the data could not be analyzed statistically because we measured in total for each group with 3 replicates, we could find that lower methane gas emissions was observed in the treatment group than in the control group from 7 to $35 \mathrm{~d}$.

\section{Discussion In vitro experiment}

This in vitro experiment was conducted to select optimal dosage of PO and SBO which could be used in in vivo experiment by considering the effect of the oils on production of methane, CLA and influence on ruminal fermentation.

In this experiment, ruminal $\mathrm{pH}$ was not affected by PO or SBO (Table 1). Some studies have reported that ruminal pH could be variously changed by highconcentrate diets in feed and the addition of fat source. High-concentrate diets supplemented with sunflower oil can promote the fermentation of rumen microbes and consequently decrease ruminal $\mathrm{pH}^{27}$. Doreau and Ferlay ${ }^{28}$ have reported that ruminal pH does not change even in high-energy diets such as SBO. As mentioned before, the variety of ruminal $\mathrm{pH}$ could be affected by changes of ruminal fermentation patterns. Considering that neither SBO nor PO affected ruminal $\mathrm{pH}$ value, these sources might not directly affect the environment of ruminal fermentation.

Results of our experiment showed that there was no significant difference in the amount of ammonia concentrate in the group treated with $0 \% \mathrm{PO}$ at $48 \mathrm{~h}$ (Table 1). However, ammonia was affected by SBO (increase of ammonia in SBO supplementation group with PO at $0.1 \%$ ). The synthesis of ruminal ammonia nitrogen is also known to be influenced by the composition of fat source. Beauchemin et al. ${ }^{29}$ reported that the supplemented fat sources can be used as an energy source for rumen microbes, affecting ruminal fermentation patterns and the synthesis of microbial protein. However, it is also known that fat additives, which can be used as an energy source, have various effects on ruminal $\mathrm{pH}$ and microbial activity, depending on the fat composition ${ }^{28}$. In this study, when considering that the ammonia- $\mathrm{N}$ concentrate was numerically higher in $0 \%$ than in $0.1 \% \mathrm{PO}$ treatments and the ammonia was increased by the SBO at $0.1 \%$ $\mathrm{PO}$ treatments, it is speculated that PO and SBO affected the synthesis of microbial protein and ammonia-N differently.

Generally, total gas production and methane levels in rumen are negatively correlated in in vitro experiments with fat supplement. This is because the fat source can facilitate ruminal lipolysis, resulting in decreased methane and increased total gas production by affecting ruminal microbes ${ }^{12,22}$. Wettstein et al. ${ }^{30}$ have reported that fat supplement in diet can reduce total gas production, which means exhausted energy. Thus, they suggested that fat supplement could improve the energy availability of microorganisms by reducing the exhausted energy in rumen. On the other hand, it has been reported that the addition of unsaturated fatty acids in feeds can act as a hydrogen sink in the rumen besides lipolysis, inducing hydrogen ions that could be used for methane production, to the process of converting unsaturated fatty acid into saturated fatty acid ${ }^{22}$.

In addition, as with PO, the essential oil has antimicrobial effects in the rumen, and results in lowering gas production during ruminal fermentation 31 Considering all these phenomena, the results of this study indicate that the reduced total gas and methane production were affected by the hydrogen sink effect and especially accelerated the lipolysis effect of the oil; the effect could be confirmed more severely at $0.1 \%$ PO and $2 \%$ SBO addition (Table 1 ).

Factors affecting VFA compositions in association with the rumen fermentation environment are various, including the ratio of forage to concentrate, high protein, carbohydrate and fat content in feed, supplemented fat composition, and so on ${ }^{30,32}$. Depending on the fermentation rate of feed in rumen, ruminal pH and VFA composition changes are associated with each other. For example, the rate of fermentation in the rumen in the case of overfeeding concentrate could be faster than that in the case of feeding low concentrate, resulting in lower ruminal $\mathrm{pH}$, lower levels of acetate and butyrate, and increased propionate ratio in the VFA composition. In particular, it has been reported that oil supplement in feed can be fermented by ruminal microbes and used as an energy source, thereby modifying the VFA composition by reducing the $\mathrm{pH}$ in the rumen ${ }^{33}$. As previously mentioned, the addition of unsaturated fatty acids in the rumen can increase the production of propionate, act as a hydrogen sink, and reduce methane production. Castillejos et al. ${ }^{34}$ have reported that antimicrobial materials such as essential oil can increase the ratio of acetate to propionate in calves fed a 6: 4 alfalfa hay: concentrate diet. In contrast, Cardozo et al. ${ }^{35}$ have observed that the ratio of acetate to propionate is decreased in calves fed a 1: 9 straw: concentrate (based on corn, barley, and soybean meal) diet

Page 5/14 
supplemented with essential oil. It has been reported that effects of essential oil on ruminal $\mathrm{pH}$ and feed composition are very diverse ${ }^{31}$. Considering these results, further research is needed to determine the effect of plant-derived essential oil on ruminal VFAs.

In results of long chain fatty acids in rumen, consecutive changes of linoleic acid were observed (Table 3). In the early stage of fermentation, TVA from linoleic acid was increased by the SBO supplement. CLA was increased by SBO and PO. Linoleic acid, which is found in SBO, is known to produce CLA and TVA through isomerization and biohydrogenation by microorganisms in the rumen ${ }^{36}$. According to Kairenius et al. ${ }^{37}$, fatty acid metabolism is affected by the composition of the added fat. Higher degree of unsaturation of the added fat causes more extensive metabolism of fatty acids. In addition, Kim et al. ${ }^{16}$ have reported that the addition of not only fat, but also antimicrobial essential oil such as PO, can induce an increase of CLA in the milk of ruminants. Taking all these studies into account, the increase of CLA in the present study might be due to effects of SBO containing a large amount of unsaturated fatty acids and PO. Furthermore, it was speculated that the most activation of inducing hydrogen sink might be occurred by $0.1 \%$ PO and $2 \%$ SBO addition when considering most decreases in methane and VFAs and increase in CLA production simultaneously.

\section{In vivo experiment}

This in vivo experiment was carried to confirm the effect of selected supplementation $(0.1 \% \mathrm{PO}$ and $2 \% \mathrm{SBO})$ in in vitro experiment on increasing milk CLA and depressing methane emission by using dairy cows.

As expected from results of in vitro experiment (Table 6), CLA percentage and CLA yield were higher in the PSO group. According to Wang et al. ${ }^{36}$, CLA in milk could be increased when linoleic acids, the same as SBO, are added to the diet. The problem is that increased t10, c12 CLA often decreases milk fat as a result of increased total CLA. In the current study, milk fat percentage was decreased. However, milk yield was higher in PSO group than control thus, amount of milk fat $(\mathrm{kg} / \mathrm{d})$ was not difference between two groups. In addition, total CLA yield was not decreased, although $\mathrm{t} 10, \mathrm{c} 12 \mathrm{CLA}$ was higher in the treatment group than that in the control group. Considering all these phenomena, PO might have induced more c9, t11 CLA isomerization than t10, c12 CLA isomerization by affecting related microbes (e.g., Butyrivibrio fibrisolvens). In addition, increased UFA and PUFA levels were observed at the same time in the treatment group. All these differences between the two groups could be explained by the amount of linoleic acid in added SBO and PO inducing hydrogen ion to isomerization of linoleic acid from what might be methanogenesis results of in vitro experiment. Thus, induced isomerization in the treatment group might have increase UFA, PUFA, and CLA compared to the control group. In addition, stearic acid was higher in the PSO group at $35 \mathrm{~d}$. This higher stearic acid could be explained by greater microbe biohydrogenation of linoleic acids in the PSO group fed more linoleic acid than the control group.

In the methane production results, one lack was the measuring methane per pen which was not individual animal, even though we tried to redress this limitation by measuring the methane 3 times during the experiment. However, interestingly, Figure 2 shows the adaptability of cows to the PSO treatment, as it shows considerable increase in $7 d$, and gradual increase after $7 d$ to the end of the experiment. Generally, the production of methane in ruminant is decreased when dietary fat is added, and it is reported that the effect is varies greatly, depending on the constituents or unsaturation of added fat ${ }^{12,22}$. As mentioned earlier, the addition of unsaturated fatty acids is known to induce fatty acid metabolism and inhibit methane production in rumen microbes. In the result of gas production in in vitro experiment, it is observed that the addition of SBO, which contains a large amount of unsaturated fatty acid, decreased methane production, and PO addition resulted in more decrease in methane. Considering the results of fatty acid in rumen and milk, the CLA enhancement effect of the two oil sources confirmed in this study may ultimately lead to a decrease in methane production, by competition of hydrogen ion between biohydrogenation and methane production.

Complete blood cell counting (CBC) is a representative physiological index of animals. It was used in this study for the purpose of verifying the safety of experimental additives through animals. Some researchers have shown that oil supplements can affect animal disease because of the negative effect of unsaturated fatty acid in rumen ${ }^{38}$. However, in this study, there were no significant differences in results of CBC (white blood cell, lymphocyte, monocyte, or other indices) between control and treatment groups containing PO and SBO. Thus, the addition of PO and SBO supplement to the diet did not lead to diseaserelated chemical changes in dairy cows (Supplemental Table S2).

Some researchers have found a relationship between fat supplement and blood metabolites ${ }^{39,40}$. According to Henderson et al. ${ }^{39}$, fat addition in ruminant diet affects the synthesis of microbial protein in rumen. The added fat is used as an energy source for protein synthesis, resulting in increasing amino acid- $\mathrm{N}$ and decreasing ammonia- $\mathrm{N}$ in the rumen, eventually reducing nitrogen content in the blood. It is known that fat degraded by lipolysis in rumen is fermented to increase propionate content in VFA compositions, thereby increasing glucose content in the blood by gluconeogenesis ${ }^{41}$. Similar to results of previous studies, the present study also showed that the PSO group containing oil supplement in feed had lower blood BUN but higher glucose concentration than the control group (Supplemental Table S3). Blood magnesium was also higher in the oil supplement group compared to the control. In general, most of the digestive and absorption lipid is transferred itself or binding to protein. However, some proportions of the lipid binding to magnesium are presented in the blood. Thus, the higher blood magnesium in our result might be affected by the oil supplement in the diet ${ }^{42}$. The reason why blood Ca showed a tendency to be significant was unknown. This parameter was inconsistent with other plasma outcomes.

Fecal microbes are microorganisms involved in the digestive physiology of livestock. Their digestibilities have been evaluated according to their populations

43. Currently, antimicrobial effects of essential oils have been extensively studied in rumen. However, their effects on post-ruminal digestive have not been studied in detail yet. Furthermore, although the essential oil PO used in the experiment is also known to have antimicrobial effects, it is not yet known whether such effect could affect the whole ruminant digestive system ${ }^{44}$. However, as shown in the present study, numbers of pathogens in fecal microbes decreased due to the addition of $\mathrm{PO}$ and SBO. This demonstrates that the antimicrobial effect of PO also affects post-ruminal digestive system. Thus, the result of decrease in pathogenic microbes by PSO could support that PO might also be able to improve the energy availability of feed in ruminant (Figure 1). 
Generally, some studies have reported that milk production is positively correlated with the energy content in feed ${ }^{45}$. As expected, this study also showed that the addition of $2 \%$ fat source, a high energy source, resulted in an increase in milk yield. Bauman ${ }^{45}$ has reported that the increase in glucose in the blood is positively correlated with milk yield. In particular, the fat supplement used in this study increased glucose in the blood by increasing propionate in the VFA composition due to the effect of SBO and PO on rumen fermentation in in vitro experiment. Furthermore, the antimicrobial effect of PO might have affected fecal microbes. Thus, PO might be able to increase milk yield by improving the energy availability of SBO and basal diet (Table 4).

From milk composition data (Table 5), milk fat content $(\mathrm{kg} / \mathrm{d})$ and $4 \%$ FCM were similar between control and treatment groups. This is different from the result of Rico and Harvatine ${ }^{15}$. This might be because SBO has an effect on milk fat depression by increasing trans-10, cis-12 CLA known to inhibit the synthesis of milk fat. In our result, the unchanged milk fat in the treatment group may be explained by the effect of PO on isomerization to cis-9, trans- 11 CLA rather than to trans-10, cis-12 CLA. Milk nitrogen is generally influenced by blood nitrogen and ammonia-N in rumen. Thus, decreased MUN in the PSO group could be explained by the flow of decreased BUN in blood (Supplemental Table S3).

In summary, a mixture of $0.1 \%$ phytoncide oil (PO) and $2 \%$ soybean oil (SBO) in diet can lead to an increase in CLA and a decrease in methane production in rumen by inducing hydrogen ion from methane production to biohydrogenation, especially isomerization of linoleic acid with no change in milk fat. Therefore, a combination of PO and SBO could result in increased milk CLA and depressed methane production with no influence on milk fat.

\section{Declarations}

\section{Acknowledgments}

This study was supported by Konkuk University 2020.

\section{Authors' contributions}

TBK and MHB conducted this study and wrote the first draft of the manuscript. JGN and JSL assisted in the farm works, reviewing and editing the manuscript. HGL designed the study and revised the manuscript. All authors read and approved the final manuscript.

\section{Competing interests}

The authors declare no conflicts of interest.

\section{Data availability}

Datasets generated during and/or analyzed during the current study are available from the corresponding author upon reasonable request.

\section{References}

1. Benchaar, C., J. Duynisveld, and E. Charmley. 2006. Effects of monensin and increasing dose levels of a mixture of essential oil compounds on intake, digestion and growth performance of beef cattle. Can. J. Anim. Sci. 86:91-96. https://doi.org/10.3168/jds.2008-1903.

2. Doyle, E. 1998. Scientific forum explores CLA knowledge. Inform 9:69-73.

3. Decker, E. A. 1995. The role of phenolics, conjugated linoleic acid, carnosine, and pyrroloquinoline quinone as nonessential dietary antioxidants. Nutrit. Rev. 53:49-58. https://doi.org/10.1111/j.1753-4887.1995.tb01502.x

4. Nicolosi, R., E. Rogers, D. Kritchevsky, J. Scimeca, and P. Huth. 1997. Dietary conjugated linoleic acid reduces plasma lipoproteins and early aortic atherosclerosis in hypercholesterolemic hamsters. Artery 22:266-277. https://doi.org/10.1016/S0271-5317(00)00268-2

5. Miller, C., Y. Park, M. Pariza, and M. Cook. 1994. Feeding conjugated linoleic acid to animals partially overcomes catabolic responses due to endotoxin injection. Biochem. Biophys. Res. Commun. 198:1107-1112. https://doi.org/10.1006/bbrc.1994.1157

6. Wang, L.-L. and E. A. Johnson. 1992. Inhibition of Listeria monocytogenes by fatty acids and monoglycerides. Appl. Environ. Microbiol. 58:624-629. https://doi.org/10.1128/aem.58.2.624-629.1992

7. Houseknecht, K. L., J. P. V. Heuvel, S. Y. Moya-Camarena, C. P. Portocarrero, L. W. Peck, K. P. Nickel, and M. A. Belury. 1998. Dietary conjugated linoleic acid normalizes impaired glucose tolerance in the Zucker diabetic fattyfa/farat. Biochem. Biophys. Res. Commun. 244:678-682.

https://doi.org/10.1006/bbrc.1998.8303

8. AbuGhazaleh, A. and L. Holmes. 2007. Diet supplementation with fish oil and sunflower oil to increase conjugated linoleic acid levels in milk fat of partially grazing dairy cows. J. Dairy Sci. 90:2897-2904. https://doi.org/10.3168/jds.2006-684

9. Abu-Ghazaleh, A., D. Schingoethe, A. Hippen, and L. Whitlock. 2002. Feeding fish meal and extruded soybeans enhances the conjugated linoleic acid (CLA) content of milk. J. Dairy Sci. 85:624-631. https://doi.org/10.3168/jds.S0022-0302(02)74116-7

10. Palmquist, D. L., A. L. Lock, K. J. Shingfield, and D. E. Bauman. 2005. Biosynthesis of conjugated linoleic acid in ruminants and humans. Adv. Food Nutr. Res. 50:179-217. https://doi.org/10.1016/S1043-4526(05)50006-8 
11. Beauchemin, K. and S. McGinn. 2006. Methane emissions from beef cattle: Effects of fumaric acid, essential oil, and canola oil. J. Anim Sci. 84:14891496. https://doi.org/10.2527/2006.8461489x

12. Martin, C., D. Morgavi, and M. Doreau. 2010. Methane mitigation in ruminants: from microbe to the farm scale. Animal. 4:351-365. https://doi.org/10.1017/S1751731109990620.

13. Davis, C. and R. Brown. 1970. Low-fat milk syndrome. Low-fat milk syndrome.

14. Bauman, D. E. and J. M. Griinari. 2003. Nutritional regulation of milk fat synthesis. Annu. Rev. Nutr. 23:203-227. https://doi.org/10.1146/annurev.nutr.23.011702.073408

15. Harvatine, K., Y. Boisclair, and D. Bauman. 2009. Recent advances in the regulation of milk fat synthesis. Animal. 3:40-54. https://doi.org/10.1017/S1751731108003133

16. Kim, M. J., U. S. Jung, S. W. Jeon, J. S. Lee, W. S. Kim, S. B. Lee, Y. C. Kim, B. Y. Kim, T. Wang, and H. G. Lee. 2016. Improvement of milk fatty acid composition for production of functional milk by dietary phytoncide oil extracted from discarded pine nut cones (Pinus koraiensis) in holstein dairy cows. Asian-australas. J. Anim. Sci. 29:1734. https://doi.org/10.5713/ajas.16.0281

17. Wallace, R. J. 2004. Antimicrobial properties of plant secondary metabolites. Proc Nutr Soc. 63:621-629. https://doi.org/10.1079/pns2004393

18. Li, H., P. Zhao, Y. Lei, M. Hossain, and I. Kim. 2015. Phytoncide, phytogenic feed additive as an alternative to conventional antibiotics, improved growth performance and decreased excreta gas emission without adverse effect on meat quality in broiler chickens. Livest Sci. 181:1-6. https://doi.org/10.1016/j.livsci.2015.10.001

19. Wallace, R. J., L. C. Chaudhary, N. McKain, N. R. McEwan, A. J. Richardson, P. E. Vercoe, N. D. Walker, and D. Paillard. 2006. Clostridium proteoclasticum: a ruminal bacterium that forms stearic acid from linoleic acid. FEMS Microbiol. Lett. 265:195-201. https://doi.org/10.1111/j.1574-6968.2006.00487.x

20. Oh, J., E. Wall, D. Bravo, and A. N. Hristov. 2017. Host-mediated effects of phytonutrients in ruminants: A review. J. Dairy Sci. 100:5974-5983. https://doi.org/10.3168/jds.2016-12341

21. Klevenhusen, F., A. Muro-Reyes, R. Khiaosa-Ard, B. Metzler-Zebeli, and Q. Zebeli. 2012. A meta-analysis of effects of chemical composition of incubated diet and bioactive compounds on in vitro ruminal fermentation. Anim. Feed Sci. Technol. 176:61-69. https://doi.org/10.1016/j.anifeedsci.2012.07.008

22. Doreau, M. and A. Ferlay. 2015. Linseed: a valuable feedstuff for ruminants. OCL 22:D611. https://doi.org/10.1051/ocl/2015042

23. McDougall, E. 1948. Studies on ruminant saliva. 1. The composition and output of sheep's saliva. Biochem. J. 43:99-109.

24. Owen, W., D. Stuckey, J. Healy Jr, L. Young, and P. McCarty. 1979. Bioassay for monitoring biochemical methane potential and anaerobic toxicity. Water Res. 13:485-492. https://doi.org/10.1016/0043-1354(79)90043-5

25. Fawcett, J. K., and Scott, J. E. (1960). A rapid and precise method for the determination of urea. Journal of clinical pathology, 13(2), 156-159. https://doi.org/10.1136/jcp.13.2.156

26. National Research Council. 2001. Nutrient requirements of dairy cattle: 2001. 7th rev. ed. Washington, DC: National Academies Press.

27. Ivan, M., P. Mir, K. Koenig, L. Rode, L. Neill, T. Entz, and Z. Mir. 2001. Effects of dietary sunflower seed oil on rumen protozoa population and tissue concentration of conjugated linoleic acid in sheep. Small Rumin. Res. 41:215-227. https://doi.org/10.1016/S0921-4488(01)00220-6

28. Doreau, M. and A. Ferlay. 1995. Effect of dietary lipids on nitrogen metabolism in the rumen: a review. Livest. Prod. Sci. 43:97-110. https://doi.org/10.1016/0301-6226(95)00041-I

29. Beauchemin, K. A., S. M. McGinn, C. Benchaar, and L. Holtshausen. 2009. Crushed sunflower, flax, or canola seeds in lactating dairy cow diets: effects on methane production, rumen fermentation, and milk production. J Dairy Sci 92:2118-2127.

30. Wettstein, H.-R., A. Machmüller, and M. Kreuzer. 2000. Effects of raw and modified canola lecithins compared to canola oil, canola seed and soy lecithin on ruminal fermentation measured with rumen simulation technique. Anim. Feed Sci. Technol. 85:153-169. https://doi.org/10.1016/S03778401(00)00149-8.

31. Calsamiglia, S., M. Busquet, P. Cardozo, L. Castillejos, and A. Ferret. 2007. Invited review: essential oils as modifiers of rumen microbial fermentation. J. Dairy Sci 90:2580-2595. https://doi.org/10.3168/jds.2006-644

32. Penner, G., M. Taniguchi, L. Guan, K. Beauchemin, and M. Oba. 2009. Effect of dietary forage to concentrate ratio on volatile fatty acid absorption and the expression of genes related to volatile fatty acid absorption and metabolism in ruminal tissue. J. Dairy Sci. 92:2767-2781. https://doi.org/10.3168/jds.2008-1716

33. Getachew, G., E. DePeters, P. Robinson, and S. Taylor. 2001. In vitro rumen fermentation and gas production: influence of yellow grease, tallow, corn oil and their potassium soaps. Anim. Feed Sci. Technol. 93:1-15. https://doi.org/10.1016/S0377-8401(01)00264-4

34. Castillejos, L., S. Calsamiglia, and A. Ferret. 2006. Effect of essential oil active compounds on rumen microbial fermentation and nutrient flow in in vitro systems. J. Dairy Sci. 89:2649-2658. https://doi.org/10.3168/jds.S0022-0302(06)72341-4

35. Cardozo, P., S. Calsamiglia, A. Ferret, and C. Kamel. 2005. Screening for the effects of natural plant extracts at different pH on in vitro rumen microbial fermentation of a high-concentrate diet for beef cattle. J. Anim Sci. 83:2572-2579. https://doi.org/10.2527/2005.83112572x

36. Wang, T., S. B. Lee, J. H. Hwang, J. N. Lim, U. S. Jung, M. J. Kim, H. S. Kang, S. H. Choi, J. S. Lee, S. G. Roh, and H. G. Lee. 2015. Proteomic analysis reveals PGAM1 altering cis-9, trans-11 conjugated linoleic acid synthesis in bovine mammary gland. Lipids 50:469-481. https://doi.org/10.1007/s11745015-4009-9

37. Kairenius, P., H. Leskinen, V. Toivonen, S. Muetzel, S. Ahvenjärvi, A. Vanhatalo, P. Huhtanen, R. Wallace, and K. J. Shingfield. 2018. Effect of dietary fish oil supplements alone or in combination with sunflower and linseed oil on ruminal lipid metabolism and bacterial populations in lactating cows. J. Dairy Sci. 101:3021-3035. https://doi.org/10.3168/jds.2017-13776

38. Church, D. C. 1988. The ruminant animal: Digestive physiology and nutrition. Prospect Heights, Ill., Waveland Press. 
39. Henderson, C., C. Stewart, and R. Hine. 1977. The effect of added tallow on the rumen digestion rate and microbial populations of sheep fed dried grass. Proc Nutr Soc. 36:148A.

40. Avila, C., E. DePeters, H. Perez-Monti, S. Taylor, and R. Zinn. 2000. Influences of saturation ratio of supplemental dietary fat on digestion and milk yield in dairy cows. J. Dairy Sci. 83:1505-1519. https://doi.org/10.3168/jds.S0022-0302(00)75023-5

41. Young, J. 1977. Gluconeogenesis in cattle: significance and methodology. J. Dairy Sci. 60:1-15. https://doi.org/10.3168/jds.S0022-0302(77)83821-6

42. Emery, R., L. Brown, and J. Bell. 1965. Correlation of milk fat with dietary and metabolic factors in cows fed restricted-roughage rations supplemented with magnesium oxide or sodium bicarbonate. J. Dairy Sci. 48:1647-1651. https://doi.org/10.3168/jds.S0022-0302(65)88543-5

43. Namkung, H., M. Li J. Gong, H. Yu, M. Cottrill, and C. De Lange. 2004. Impact of feeding blends of organic acids and herbal extracts on growth performance, gut microbiota and digestive function in newly weaned pigs. Can. J. Anim. Sci. 84:697-704. https://doi.org/10.4141/A04-005

44. Kim, M. J., U. S. Jung, J. S. Lee, S. W. Jeon, W. S. Kim, B. K. An, E. J. Kim, T. Wang, B. Y. Kim, and J. T. Im. 2018. Effects of dietary phytoncides extracted from Korean pine (Pinus koraiensis) cone on performance, egg quality, gut microflora, and immune response in laying hens. J Anim Physiol Anim Nutr (Berl) 102:1220-1231. https://doi.org/10.1111/jpn.12934

45. Bauman, D. 2000. Regulation of nutrient partitioning during lactation: homeostasis and homeorhesis revisited. Ruminant physiology: digestion, metabolism, growth and reproduction:311-328. https://doi.org/10.1079/9780851994635.0311

46. Rico, D. E. and K. J. Harvatine. 2013. Induction of and recovery from milk fat depression occurs progressively in dairy cows switched between diets that differ in fiber and oil concentration. J. Dairy Sci. 96:6621-6630. https://doi.org/10.3168/jds.2013-6820

\section{Tables}

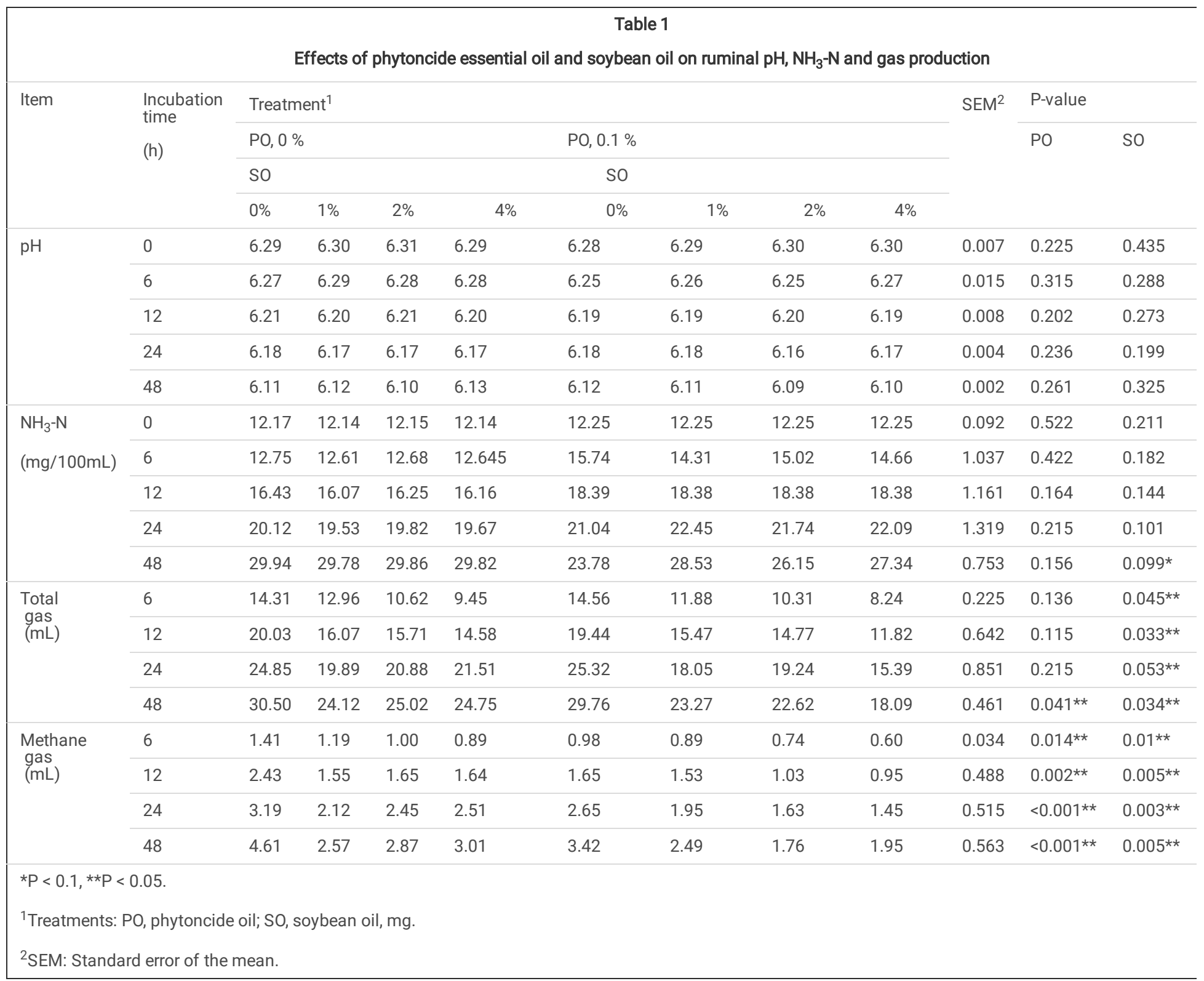


Effects of phytoncide essential oil and soybean oil on volatile fatty acid (VFA) in rumen fluid

\begin{tabular}{|c|c|c|c|c|c|c|c|c|c|c|c|c|}
\hline \multirow[t]{4}{*}{ Item } & \multicolumn{8}{|c|}{ Treatment } & \multirow[t]{4}{*}{ SEM } & \multicolumn{3}{|l|}{ P-value } \\
\hline & \multicolumn{4}{|c|}{ PO, $0 \%$} & \multicolumn{4}{|c|}{ PO, $0.1 \%$} & & \multirow[t]{3}{*}{ PO } & \multirow[t]{3}{*}{ so } & PO \\
\hline & \multicolumn{4}{|l|}{ so } & \multicolumn{4}{|l|}{ so } & & & & \multirow{2}{*}{$\stackrel{x}{\text { SO }}$} \\
\hline & $0 \%$ & $1 \%$ & $2 \%$ & $4 \%$ & $0 \%$ & $1 \%$ & $2 \%$ & $4 \%$ & & & & \\
\hline \multicolumn{13}{|c|}{ Individual VFAs (mM) at $48 \mathrm{~h}$} \\
\hline Acetic acid (C2) & 90.40 & 83.82 & 85.23 & 86.75 & 78.25 & 78.42 & 77.82 & 78.43 & 3.611 & 0.716 & 0.265 & 0.451 \\
\hline Propionic acid (C3) & 41.31 & 38.92 & 40.12 & 40.39 & 39.72 & 36.85 & 35.22 & 37.53 & 2.643 & $0.096 *$ & 0.243 & 0.398 \\
\hline Iso-butyric acid (C4) & 0.45 & 0.43 & 0.43 & 0.55 & 0.32 & 0.36 & 0.37 & 0.46 & 0.551 & 0.671 & 0.36 & 0.256 \\
\hline Butyric acid (C4) & 19.59 & 18.91 & 20.65 & 19.99 & 17.77 & 18.72 & 20.37 & 19.22 & 1.422 & 0.491 & $0.082^{*}$ & 0.682 \\
\hline Iso-valeric acid (C5) & 3.73 & 3.58 & 3.70 & 3.94 & 3.43 & 3.65 & 3.67 & 3.85 & 0.242 & 0.888 & 0.382 & 0.399 \\
\hline Valeric acid (C5) & 2.68 & 2.54 & 2.67 & 2.90 & 2.66 & 3.00 & 2.84 & 3.10 & 0.201 & 0.168 & 0.486 & 0.174 \\
\hline$A: P(C 2 / C 3)$ & 2.19 & 2.15 & 2.12 & 2.15 & 1.97 & 2.13 & 2.21 & 2.09 & 1.37 & 0.132 & 0.344 & 0.281 \\
\hline \multicolumn{13}{|c|}{${ }^{1}$ Treatments: PO, phytoncide oil; So, soybean oil, mg. } \\
\hline
\end{tabular}


Table 3

Effects of phytoncide essential oil and soybean oil on long chain fatty acids (LCFAs) in rumen fluid

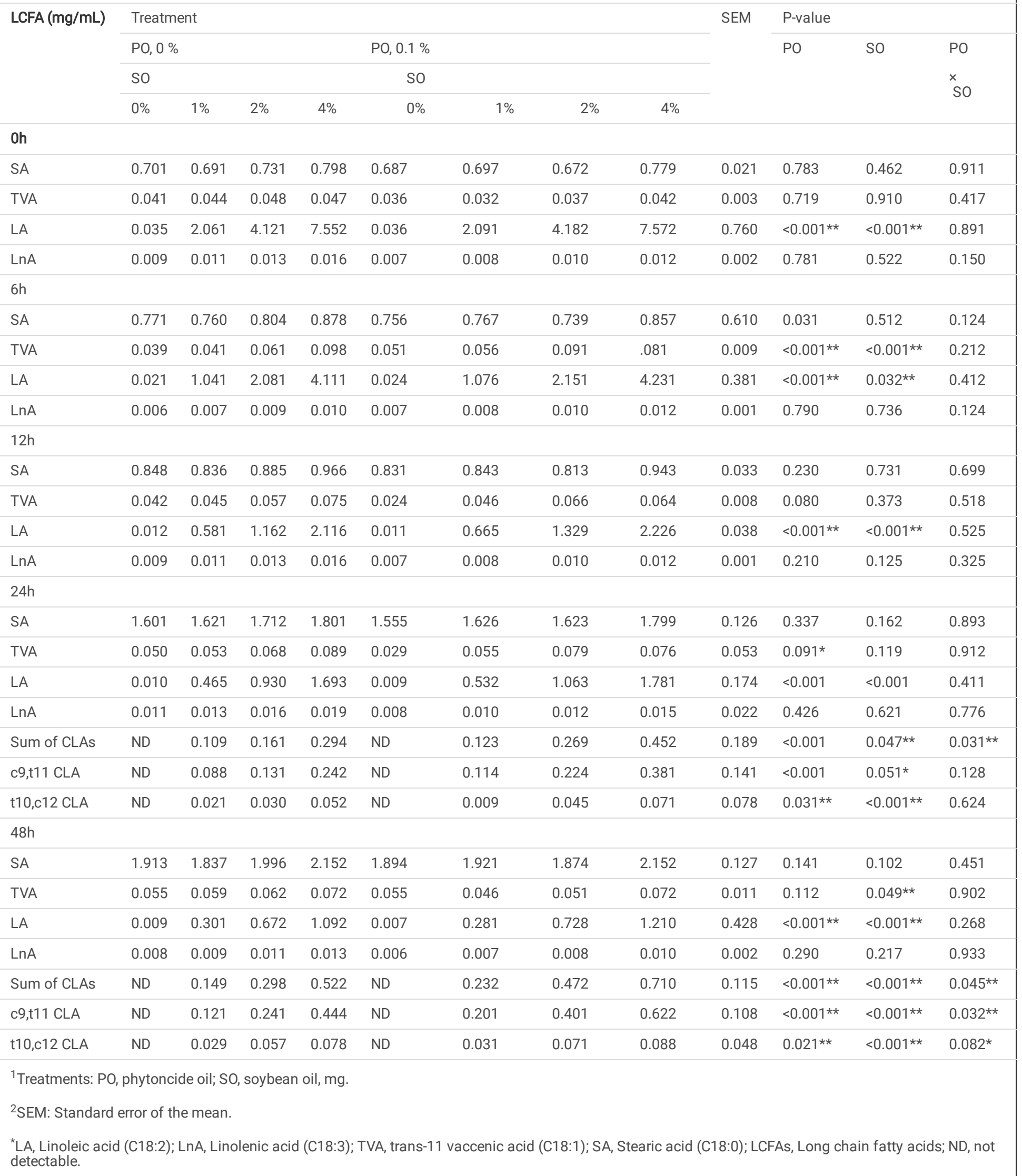


Effect of the mixture material on milk yield in dairy cow

\begin{tabular}{lllll} 
Period (d) & Control & PSO $^{1}$ & SEM & P-value \\
\cline { 2 - 3 } & \multicolumn{2}{c}{ Milk yield, kg } & & \\
\hline 0 & 33.6 & 34.3 & 1.32 & 0.807 \\
\hline $1-7$ (AVG) & 34.0 & 35.0 & 1.31 & 0.334 \\
\hline 8-14 (AVG) & 33.9 & 35.1 & 1.25 & 0.202 \\
\hline $15-21($ AVG) & 32.7 & 35.8 & 1.32 & $<0.01$ \\
\hline 22-28 (AVG) & 32.2 & 35.9 & 1.37 & $<0.01$ \\
\hline $29-35($ AVG) & 32.8 & 35.4 & 1.34 & 0.012 \\
\hline $1-35($ AVG) & 33.1 & 35.4 & 1.30 & 0.017
\end{tabular}

${ }^{1} \mathrm{PSO}$ : group fed TMR with $0.1 \% \mathrm{PO}$ and $2 \% \mathrm{SBO}$ as DM basis

Table 5

Changes in milk compositions of dairy cows given diet containing a mixture of $0.1 \% \mathrm{PO}$ and $2 \% \mathrm{SO}$ for 35 days

\begin{tabular}{|c|c|c|c|c|c|c|c|c|c|c|c|}
\hline \multirow[t]{3}{*}{ Items $^{2}(\%)$} & \multicolumn{3}{|c|}{ Control } & \multirow[t]{3}{*}{ SEM } & \multicolumn{3}{|l|}{$\mathrm{PSO}^{1}$} & \multirow[t]{3}{*}{ SEM } & \multicolumn{3}{|c|}{ P-value } \\
\hline & $0 \mathrm{~d}$ & $21 \mathrm{~d}$ & $35 d$ & & $0 \mathrm{~d}$ & $21 \mathrm{~d}$ & $35 d$ & & PSO & Days & $P \times D$ \\
\hline & & & & & & & & & $(P)$ & (D) & \\
\hline Milk fat & 5.2 & 5.0 & 5.3 & 0.13 & 5.6 & 4.2 & 4.2 & 0.20 & 0.021 & $<0.01$ & 0.013 \\
\hline $4 \%$ FCM $(\mathrm{kg} / \mathrm{d})$ & 38.0 & 35.4 & 37.5 & 1.89 & 44.4 & 38.5 & 38.0 & 2.32 & 0.291 & 0.487 & 0.734 \\
\hline $\begin{array}{l}\text { Milk fat } \\
(\mathrm{kg} / \mathrm{d})\end{array}$ & 1.7 & 1.5 & 1.7 & 0.09 & 2.0 & 1.6 & 1.5 & 0.11 & 0.576 & 0.205 & 0.450 \\
\hline Milk protein & 3.4 & 3.2 & 3.3 & 0.04 & 3.4 & 3.2 & 3.4 & 0.04 & 0.572 & 0.007 & 0.719 \\
\hline Lactose & 4.7 & 4.4 & 4.7 & 0.03 & 4.7 & 4.4 & 4.8 & 0.04 & 0.973 & 0.022 & 0.732 \\
\hline SNF & 8.6 & 8.3 & 8.7 & 0.05 & 8.7 & 8.2 & 8.8 & 0.07 & 0.694 & 0.015 & 0.626 \\
\hline SCs & 106.7 & 193.3 & 208.5 & 41.94 & 128.4 & 628.2 & 233.5 & 141.12 & 0.277 & 0.259 & 0.421 \\
\hline MUN & 18.6 & 17.0 & 20.7 & 0.36 & 18.1 & 12.4 & 16.8 & 0.47 & $<0.01$ & $<0.01$ & $<0.01$ \\
\hline Acetone & 0.003 & 0 & 0.007 & 0.00 & 0 & 0 & 0.026 & 0.01 & 0.146 & $<0.01$ & 0.062 \\
\hline $\mathrm{BHB}$ & 0.001 & 0 & 0 & 0.00 & 0 & 0 & 0.003 & 0.00 & 0.531 & 0.502 & 0.283 \\
\hline B-Casein & 2.6 & 2.5 & 2.6 & 0.03 & 2.67 & 2.5 & 2.62 & 0.04 & 0.764 & 0.011 & 0.618 \\
\hline
\end{tabular}

${ }^{1}$ PSO: group fed TMR with $0.1 \% \mathrm{PO}$ and $2 \% \mathrm{SBO}$ as DM basis

${ }^{2}$ Items: SNF, solid-not-fat; MUN, milk urea nitrogen; BHB, B-Hydroxybutyrate.

Table 6

Changes in milk fatty acids of dairy cows given diet containing a mixture of $0.1 \%$ PO and $2 \%$ SO for 35 days 


\begin{tabular}{|c|c|c|c|c|c|c|c|c|c|c|c|}
\hline \multirow[t]{3}{*}{ items } & \multicolumn{3}{|c|}{ Control } & \multirow[t]{3}{*}{ SEM } & \multicolumn{3}{|c|}{$\mathrm{PSO}^{1}$} & \multirow[t]{3}{*}{ SEM } & \multicolumn{3}{|c|}{ P-value } \\
\hline & $0 \mathrm{~d}$ & $21 \mathrm{~d}$ & $35 \mathrm{~d}$ & & $0 d$ & $21 \mathrm{~d}$ & $35 d$ & & PSO & Days & $P \times D$ \\
\hline & & & & & & & & & $(\mathrm{P})$ & (D) & \\
\hline \multicolumn{12}{|l|}{$\%$ of total FAs } \\
\hline $\begin{array}{l}\text { STA } \\
\text { (stearic acid) }\end{array}$ & 0.12 & 0.19 & 0.12 & 0.010 & 0.14 & 0.15 & 0.17 & 0.010 & 0.049 & 0.017 & 0.295 \\
\hline TVA (Trans vaccenic acid) & 3.03 & 1.39 & 0.83 & 0.417 & 2.24 & 1.20 & 1.10 & 0.589 & $<0.01$ & $<0.01$ & $<0.01$ \\
\hline C18:2n6t (Linolelaidic) & 0.45 & 0.81 & 0.21 & 0.051 & 0.42 & 0.80 & 0.37 & 0.072 & $<0.01$ & $<0.01$ & 0.003 \\
\hline C18:2n6c (Linoleic) & 0.18 & 0.15 & 0.03 & 0.181 & 0.42 & 0.09 & 0.04 & 0.162 & 0.146 & 0.004 & 0.378 \\
\hline cis-9, trans-11-CLA ${ }^{2}$ & 0.29 & 0.38 & 0.37 & 0.031 & 0.39 & 0.55 & 0.65 & 0.044 & 0.437 & $<0.01$ & $<0.01$ \\
\hline trans-10, cis-12-CLA & 0.02 & 0.02 & 0.01 & 0.011 & 0.06 & 0.02 & 0.05 & 0.015 & 0.048 & 0.311 & 0.041 \\
\hline SFA (Saturated fatty acids) & 36.26 & 37.94 & 31.54 & 1.124 & 33.66 & 32.67 & 25.42 & 1.215 & $<0.01$ & $<0.01$ & 0.547 \\
\hline UFA (Unsaturated fatty acids) & 63.57 & 61.41 & 68.28 & 1.140 & 68.11 & 67.90 & 74.34 & 1.634 & $<0.01$ & 0.014 & 0.911 \\
\hline PUFA & 1.64 & 2.08 & 1.42 & 0.103 & 2.29 & 2.39 & 2.10 & 0.076 & $<0.01$ & $<0.01$ & 0.387 \\
\hline CLA & 0.31 & 0.39 & 0.38 & 0.035 & 0.45 & 0.57 & 0.70 & 0.049 & 0.922 & $<0.01$ & $<0.01$ \\
\hline
\end{tabular}

\section{Figures}

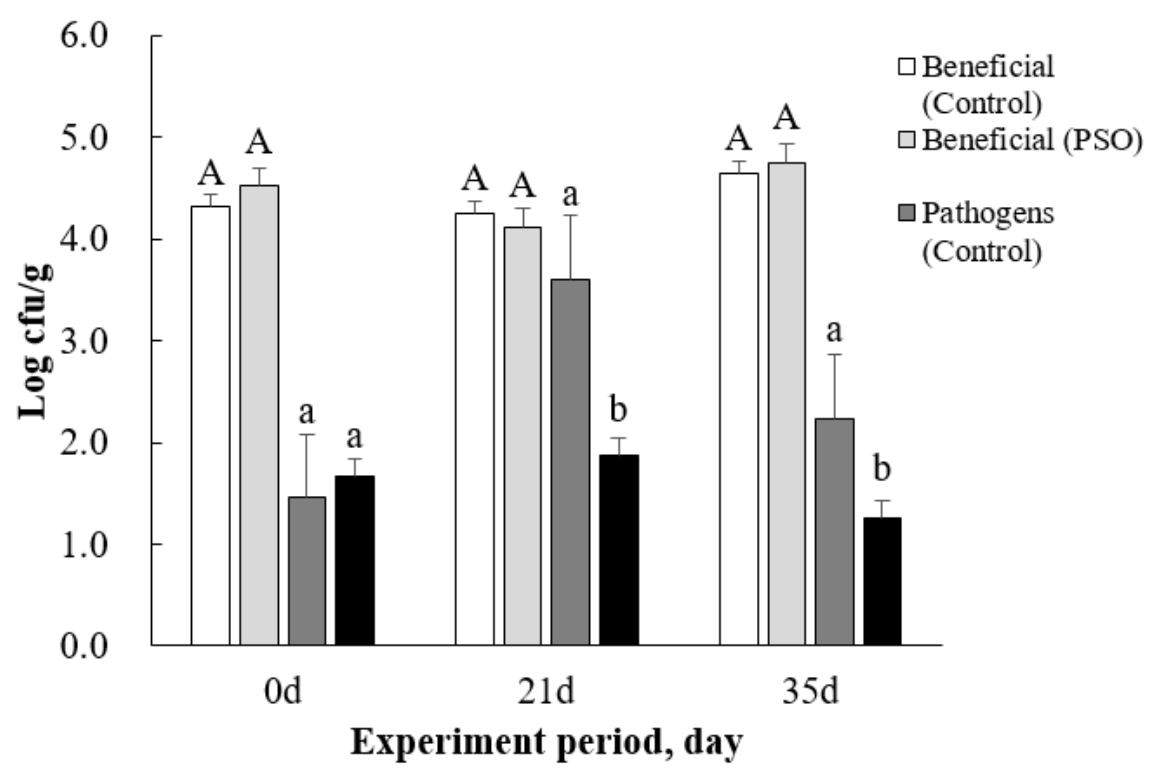

\section{Figure 1}

Effects of the mixture on fecal coliform and beneficial microbe population (35 days). Values are expressed as means. Contrasts of the same microbes between Control and PSO in each period are shown (e.g. Beneficial-Control vs Beneficial-PSO). *Differences in superscript indicate significance at $P<0.05$. Beneficial fecal microbes: Bacillus and L. bacillus spp; Pathogenic fecal microbes: E. coli and Salmonella spp. 


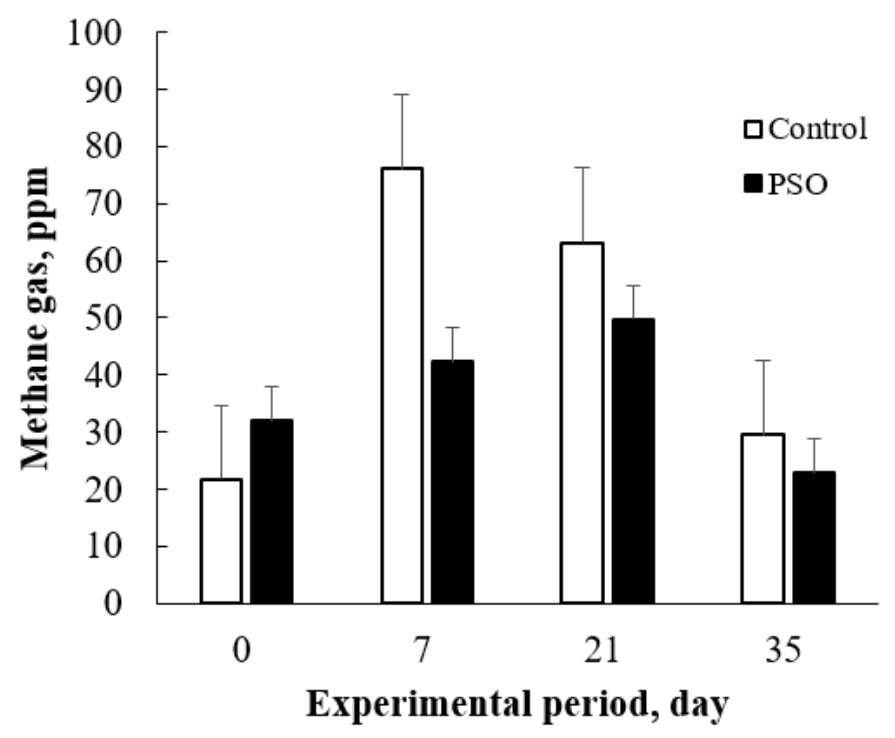

Figure 2

Changes in methane gas $\left(\mathrm{CH}_{4}\right)$ of dairy cows fed with a mixture of $0.1 \% \mathrm{PO}$ and $2 \% \mathrm{SO}$ for 35 days. Values are expressed as the mean of methane production from all cows in each treatment.

\section{Supplementary Files}

This is a list of supplementary files associated with this preprint. Click to download.

- SupplementalTables.docx 